\title{
Analgesic Effect of Alcoholic Extract of Morus alba L. Leaf on Male Rats
}

\author{
Mohammadifar M. ${ }^{1}$ BSc, Tamtaji O.R. ${ }^{2}$ BSc, Behnam M.2 BSc, Taghizadeh M.1 PhD, Talae S.A.* PhD \\ *Physiology Research Center, Kashan University of Medical Sciences, Kashan, Iran \\ 1Biochemistry and Nutrition in Metabolic Diseases Research Center, \\ Kashan University of Medical Sciences, Kashan, Iran \\ ${ }^{2}$ Physiology Research Center, Kashan University of Medical Sciences, Kashan, Iran
}

\begin{abstract}
Aims: As effective herbal materials, flavonoids and the phenolic compounds are with anti-pain and anti-inflammatory effects. Based on the studies, there is a huge amount of polyphenols and flavonoids in the leaves of Morus alba L. Therefore, the aim of this study was to investigate the anti-pain effects of alcoholic extract of the leaves of Morus alba L. on the rats.

Materials \& Methods: In the experimental study, 32 male Wistar rats were divided into 4 groups including control group and groups receiving 100, 200, and $400 \mathrm{mg} / \mathrm{kg}$ alcoholic extract of the leaves of Morus alba L. There was 4week daily extract gavage. The anti-pain effect of the extract was investigated through thermal hyperalgesia, writhing, tail flick, and formalin tests. Data was analyzed by SPSS 16 software using one-way ANOVA and Tukey's post-hoc tests.

Findings: Daily use of 100,200 , and $400 \mathrm{mg} / \mathrm{kg}$ of alcoholic extract of the leaves of Morus alba L. for 4 weeks led to significant increases in the mean foot withdrawal latency $(p<0.001)$ and mean tail withdrawal latency $(p<0.001)$ and significant reductions in the percentage of abdominal constriction $(p<0.001)$ and pain feeling in both acute $(\mathrm{p}<0.05)$ and chronic $(\mathrm{p}<0.01)$ phases of formalin test than control group. Nevertheless, the effect of $200 \mathrm{mg} / \mathrm{kg}$ dose was higher than the other doses.

Conclusion: Oral consumption of the alcoholic extract of the leaves of Morus alba L. leads to a reduction in pain feeling in the rats. In addition, the anti-pain effect of $200 \mathrm{mg} / \mathrm{kg}$ dose is higher than other doses.
\end{abstract}

\section{Keywords}

Analgesics [http://www.ncbi.nlm.nih.gov/mesh/68000700];

Morus [http://www.ncbi.nlm.nih.gov/mesh/68031625];

Rats [http://www.ncbi.nlm.nih.gov/mesh/68051381]

\author{
* Corresponding Author \\ Tel: +983155621157 \\ Fax: +983155621157 \\ Address: Physiology Research Center, Kashan University of Medical Sciences, Qotbe Ravandi Boulevard, Kashan, Iran \\ talaei@kaums.ac.ir \\ Received: July 20, $2015 \quad$ Accepted: January 11, $2016 \quad$ ePublished: March 5, 2016
}




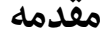

درد از مكانيزمهاى دفاعى بدن است كه بههنكام آسيب بافتى ايجاد

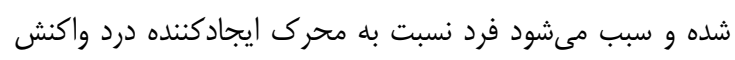

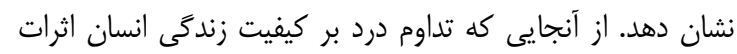

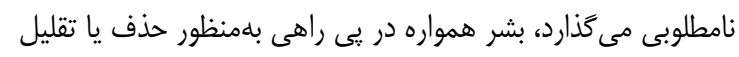

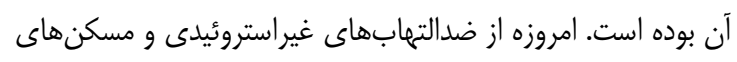

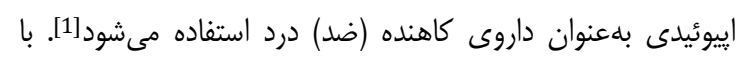

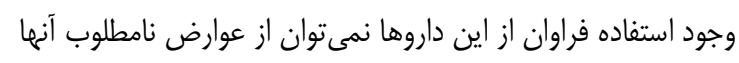

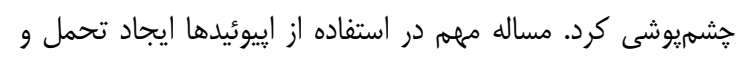

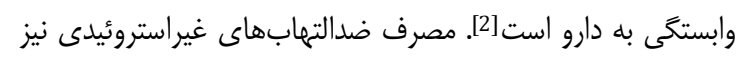

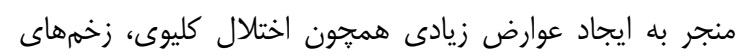

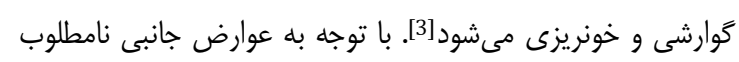

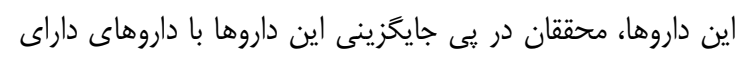

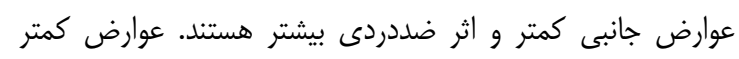

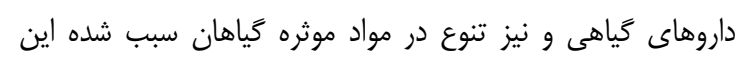

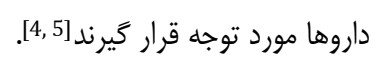

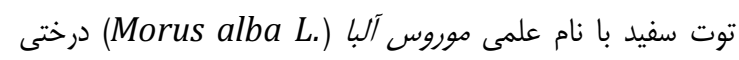

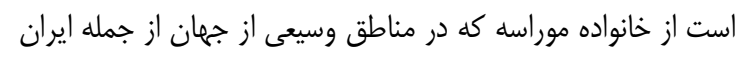

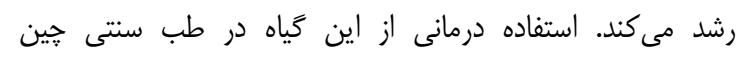

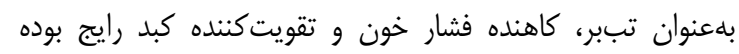

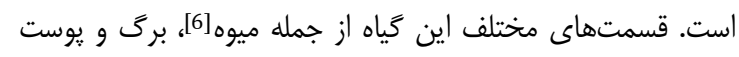

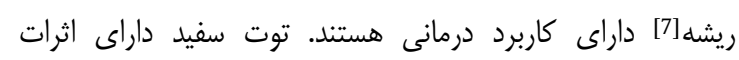

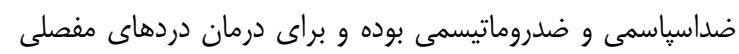
استفاده مىشود [6].

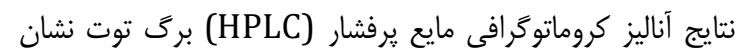

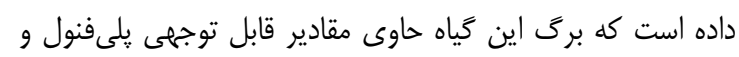

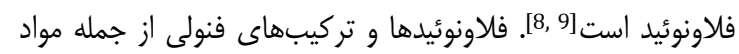

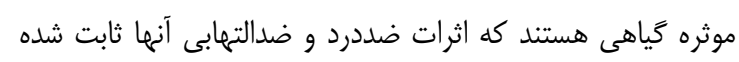

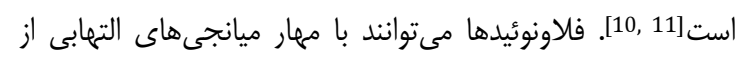

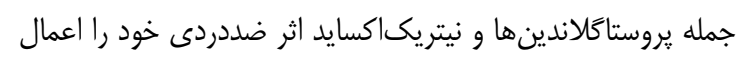

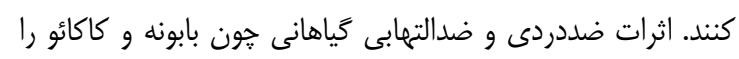

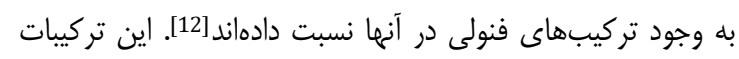

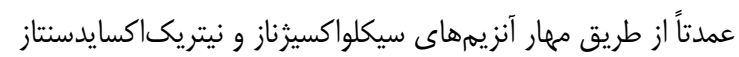

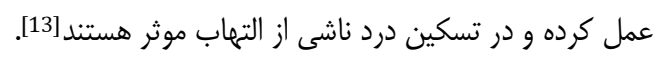

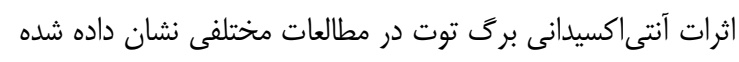

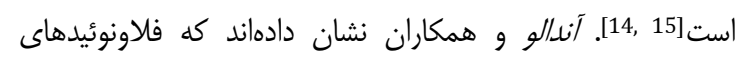

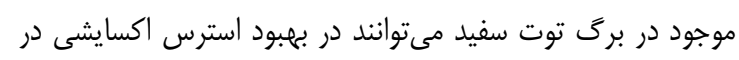

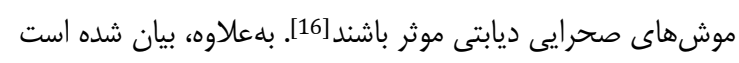

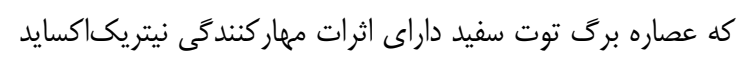

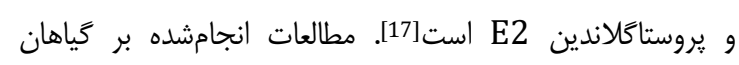

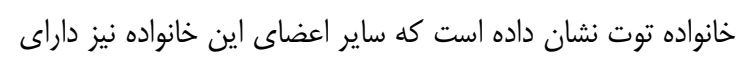

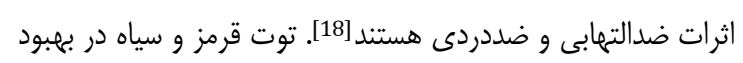

اثر ضددردى عصاره الكلى برى توتى تون سفيد بران

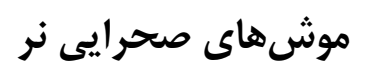

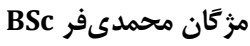

مركز تحقيقات بيوشيمى و تتذيه در بيمارى هانى متابوليك، دانشخاه علوم يزشكى كاشان، كاشان، ايران

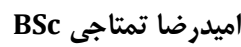
مركز تحقيقات فيزيولوزى، دانشكاه علوم يزشكى كاشان، كاشان، ايران

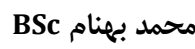
مركز تحقيقات فيزيولوزى، دانشكاه علوم يزشكى كاشان، كاشان، ايران محسن تقىز اده PhD

مركز تحقيقات بيوشيمى و تتذيه در بيمارى هادى متابوليك، دانشكاه علوم يزشكى كاشان، كاشان، ايران

PhD " ميدعليرضا طلائى مركز تحقيقات فيزيولوزى، دانشاه علوم بزشكى كاشان، كاشان، ايران

جكيده

اهداف: فلاونوئيدها و تركيبات فنولى از جمله مواد موثره كياهى هستند

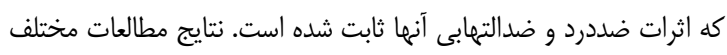

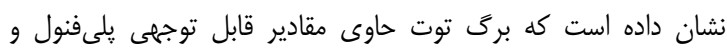

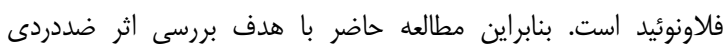
عصاره الكلى بركَ توت سفيد در موش هائ صحر ايى انجام شدان.

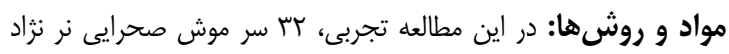

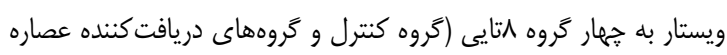

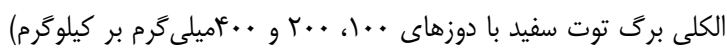

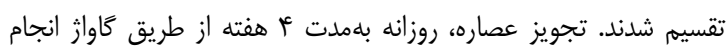

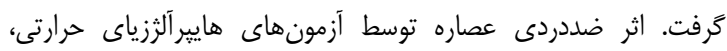

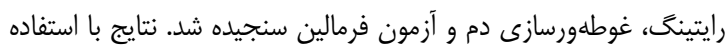

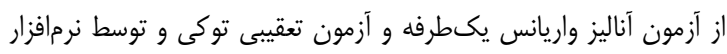
SPSS 16

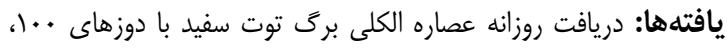

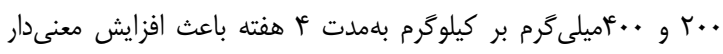

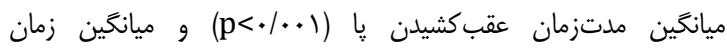

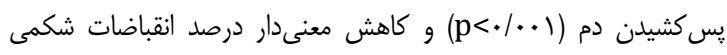
(p</.+1)

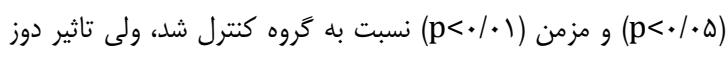

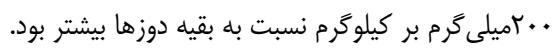

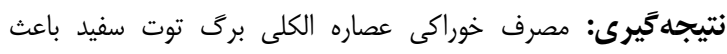

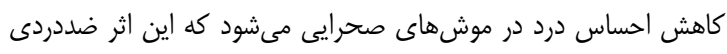

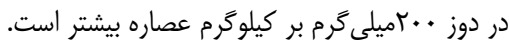

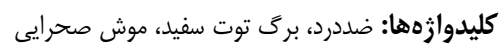

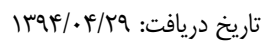
تاريخ بذيرش: |تاريخ: talaei@kaums.ac.ir :نويسنده مسئول: 


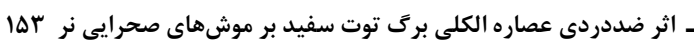

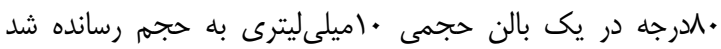

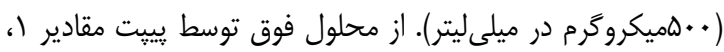

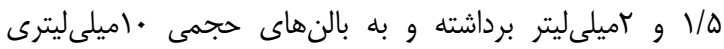

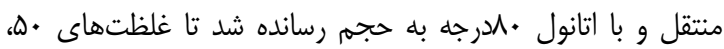

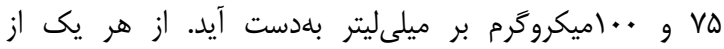

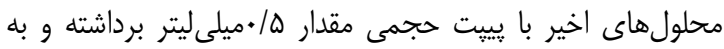
بالن حجمى هميلىليترى انتقال داده شد. سيس به آنس آن اميلىليتر

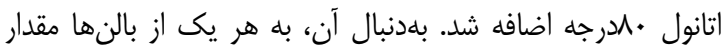

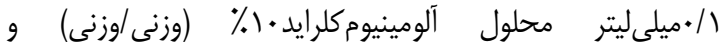

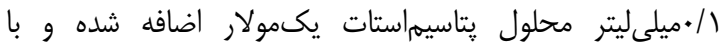

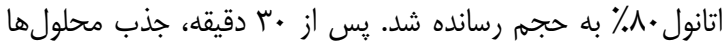

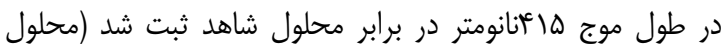
شاهد شامل كليه اجزا بهجز محلول نمونه است كه همزمان با بقيه

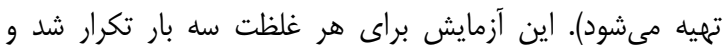
ميانگين جذب هر غلظت براى رسم منحنى كاليبراسيون به كار برده

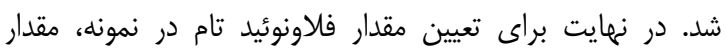
مشخصى از نمونه درون يك بالن رفلاكس •مميلىليترى توزين

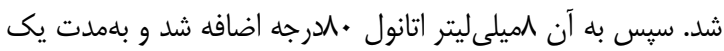
ساعت رفلاكس شد. يس از سردشدن مخلوط بلوسيله كاغذ صافى واتمن نمره • + ب به داخل يك بالن حجمى • اميلىليترى صاف شد.

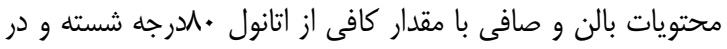

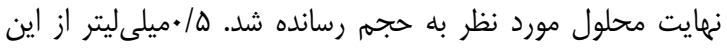
محلول توسط يييت به بالن حجمى هميلى ليترى منتقل شد و مشابه

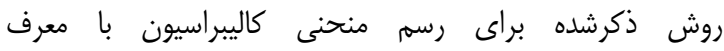

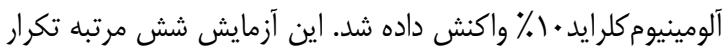

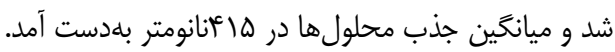
تعيين مقدار تركيبات فنوليك تام براساس كاليكاسيد: براى رسم

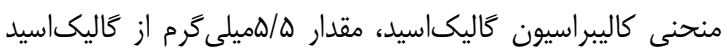

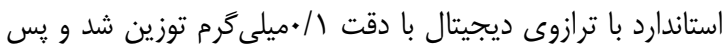

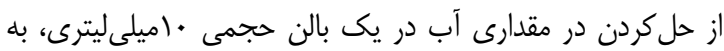

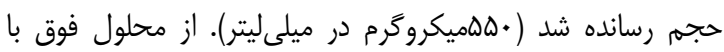

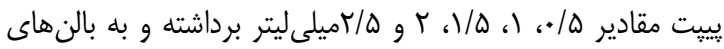

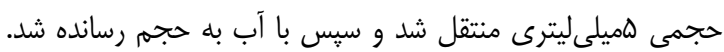
بدين ترتيب محلولهاى استاندارد از كاليكاسيد با غلظتهاى هذهـ

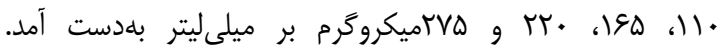

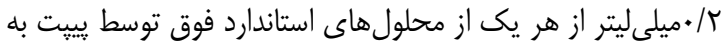

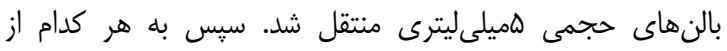

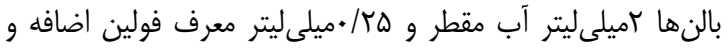

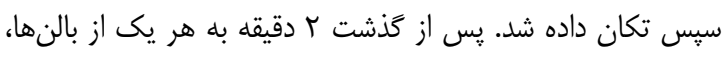

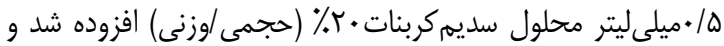

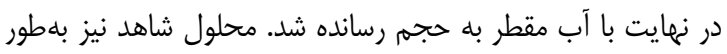

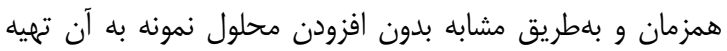

استرس اكسايشى موثر بوده و نقش آنتىاكسيدانى دارند[19].

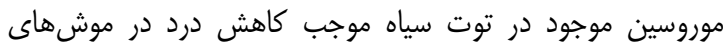
آزمايشگاهى شده است [20]. با توجه به خواص درمانى برى توت و نيز آثرات آثرات نامطلوب داروهاى ناركوتيك و ضدالتهابهاى غيراستروئيدى، مطالعه حاضر با هدف

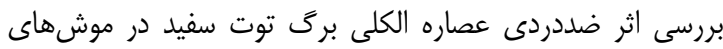

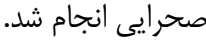

\section{مواد و روشها}

در اين مطالعه تجربى از بس سر موش صحرايى نر نزاد ويستار

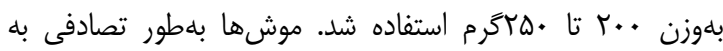

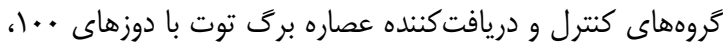

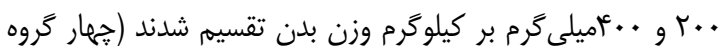

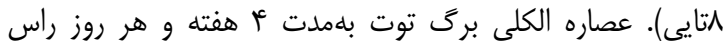
ساعت • ا صبح بلصورت كاواز تجويز شد. طى اين مدت به كروه

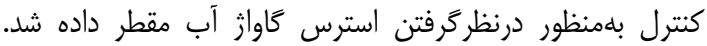

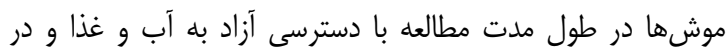

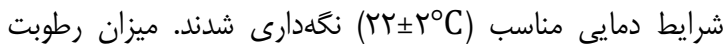

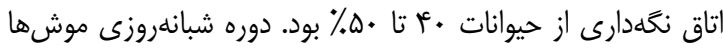
بلهورت تمامى دستورات اخلاقى مصوب كميته اخلاق معاونت يثوهشى

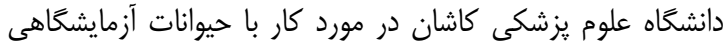

رعايت شد.

تهيه عصاره الكلى برَى توت سفيد: مقدار • بكيلوگرم برى توت سفيد واريته دانهدار از شهر كاشان تهيه شده و يس از تاييد كونه و واريته آن توسط كارشناس كشاورزى مركز تحقيقات كياهان

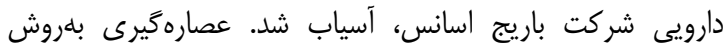

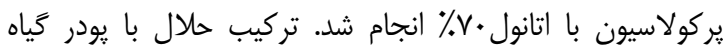

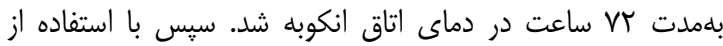

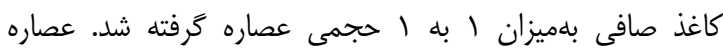

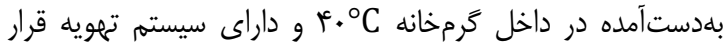

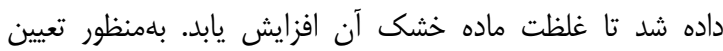

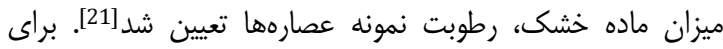

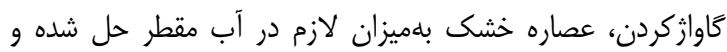
مورد استفاده قرار مى آناليز عصاره: براى آناليز عصاره، مقدار فلاونوئيدهاى تام براساس كوئرستين و مقدار تركيبات فنوليك تام براساس كاليكاسيد

بلهورت زير تعيين شد: تعيين مقدار فلاونوئيدهاى تام براساس كوئرستين: ابتدا براى رسم منحنى كاليبراسيون كوئرستين در واكنش با معرف آلومينيومكلرايد، هميلى / /ميلى 


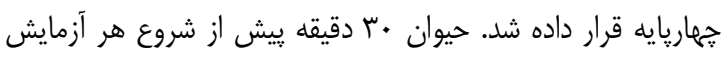

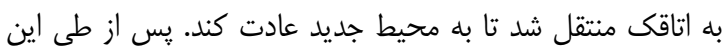

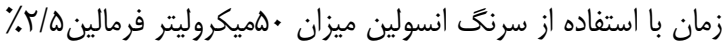

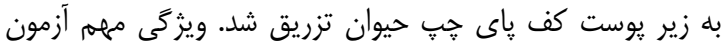

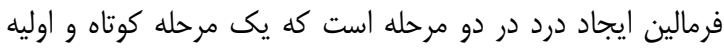

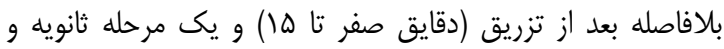

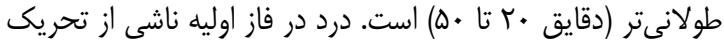

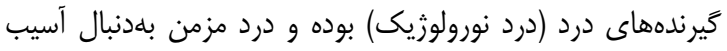
بافتى ناشى از تزريق فرمالين و التهاب ايجاد مى شود (درد التهابى).

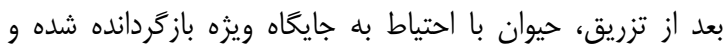

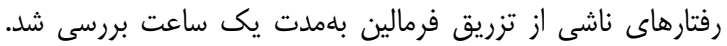

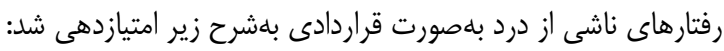

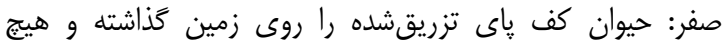
علامتى مبنى بر احساس درد نشان نداد تردي

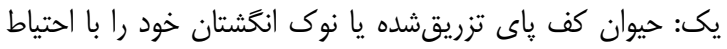

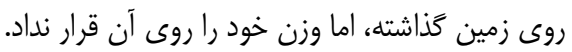

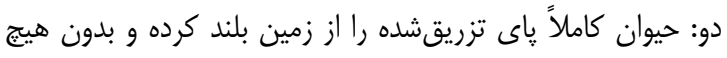

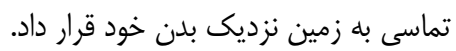

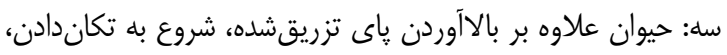

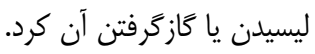

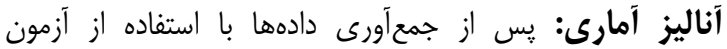

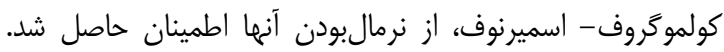

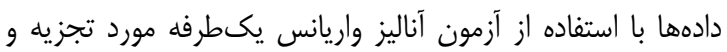

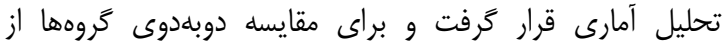

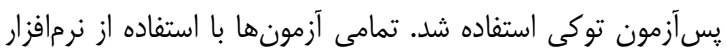
SPSS 16

يافتهها

ميانكَين مدتزمان تاخير در عقبكثشيدن پإ در كروههاى

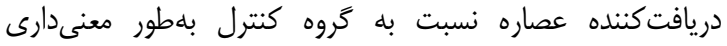

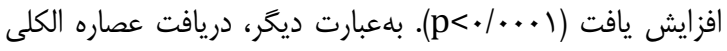

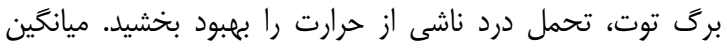

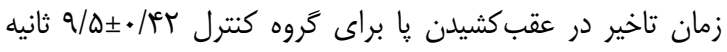

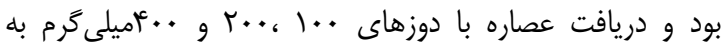

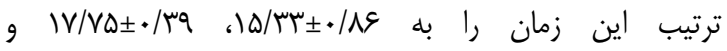
|

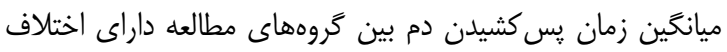

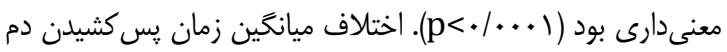

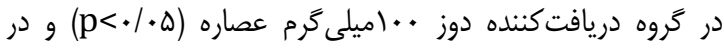

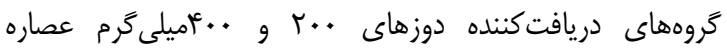

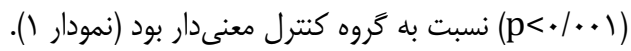

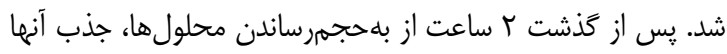

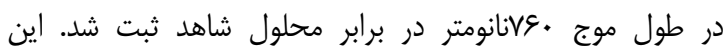

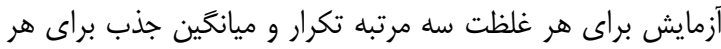

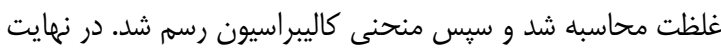
بهمنظور تعيين مقدار تركيبات فنوليك تام در نمونه، مقدار مشخصى

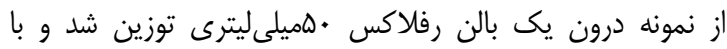

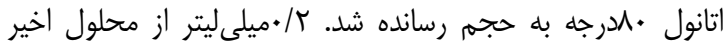
توسط بييت حجمى به بالن زوزه هميلى ليترى منتقل و مشابه روش

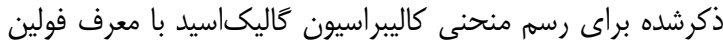

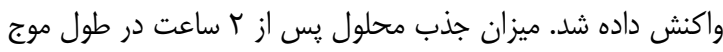
.

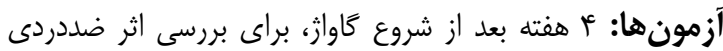

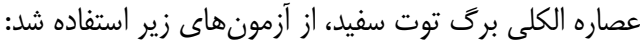

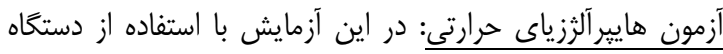

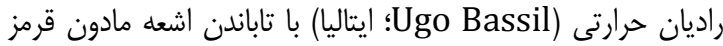

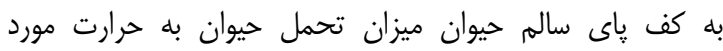

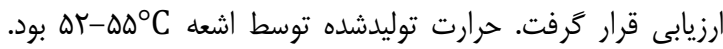

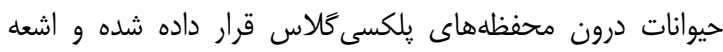

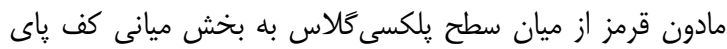

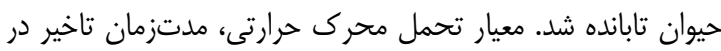

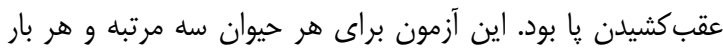
بهفاصله ه تا •ا دقيقه تكرار شد و نقطه برش آزمايش كائ بر ثانيه بود [22]. آزمون غوطهورسازى دم: در اين آزمون حيوانات درون مقيدكننده

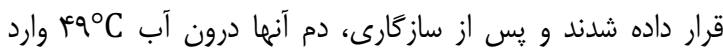

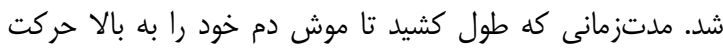

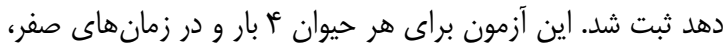

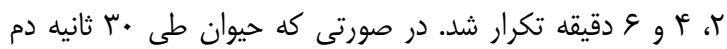
خود را تكان نمى داد براى جلوكيرى از آسيب دم، حيوان تا ب دقيقه

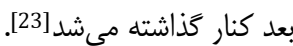

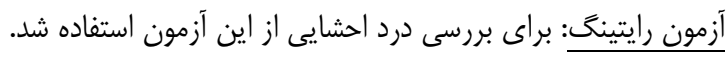

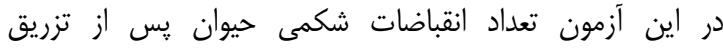

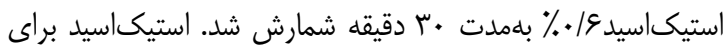

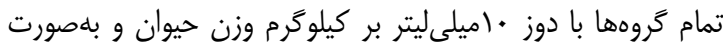

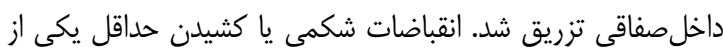

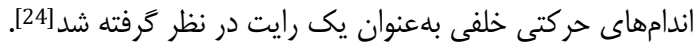

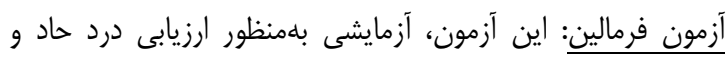

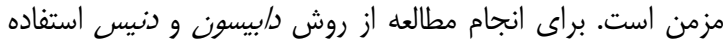

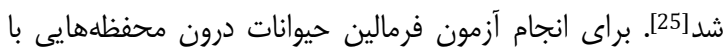

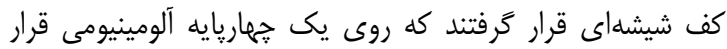
داشت. براى آسانترشدن مشاهدات يك آينه با زاويه هأدرجه درونئ 


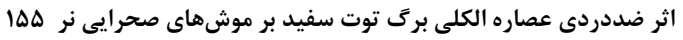

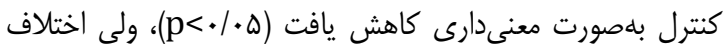

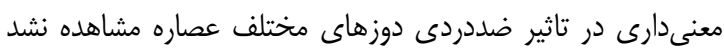

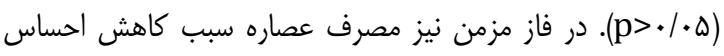

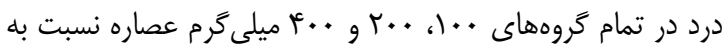

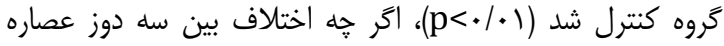

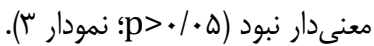

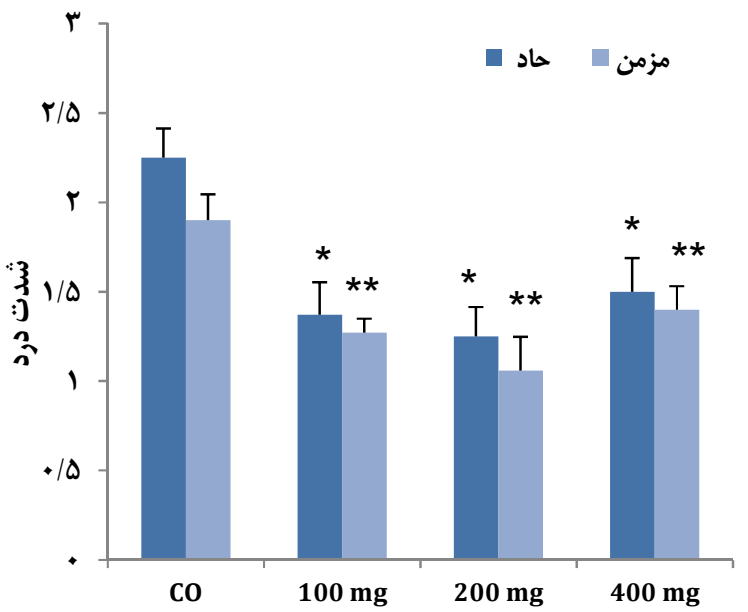

نمودار سץ) تاثير دريافت دوزهاى مختلف عصاره الكلى برگ توت سفيد بر درد

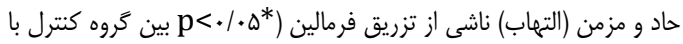

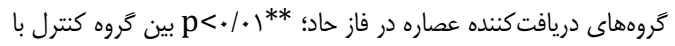

كروههاى دريافت كننده عصاره در فاز مزمنا عاده

بحث

نتايج حاصل از اين مطالعه نشان داد كه عصاره الكلى برگ توت

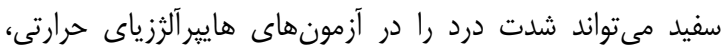
غوطهورسازى دم، رايتينگ و فرمالين كاهش دهد.

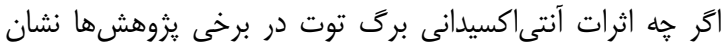

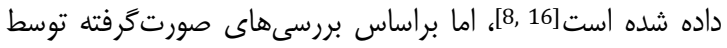
ما تاكنون يثوهشى بلمنظور بررسى اثر ضددردى برى توت توت سفيد

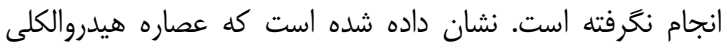
برى توت سفيد مىتواند از التهاب ناشى از تزريق كاراجينان در

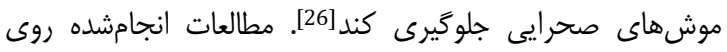
بعضى ديخر از گياهان اين خانواده حاكى از اثر ضددرد و ضدالتهابى

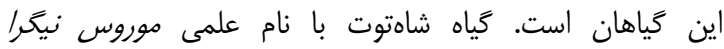
(Morus nigra L.) در مطالعهاى بيان شده است كه دوز ·. ."اميلى گرم عصاره برى

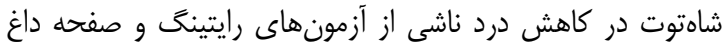
حتى نسبت به مورفين (•اميلى گرم بر كيلوگرم) و ايندومتاسين

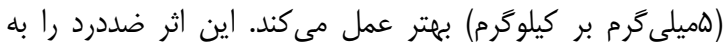

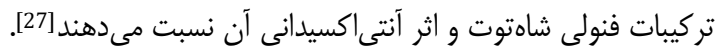

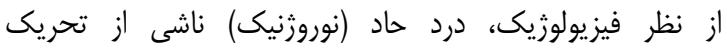
گيرندهاى عصبى محيطى بوده و درد مزمن ناشى از آزادسازى

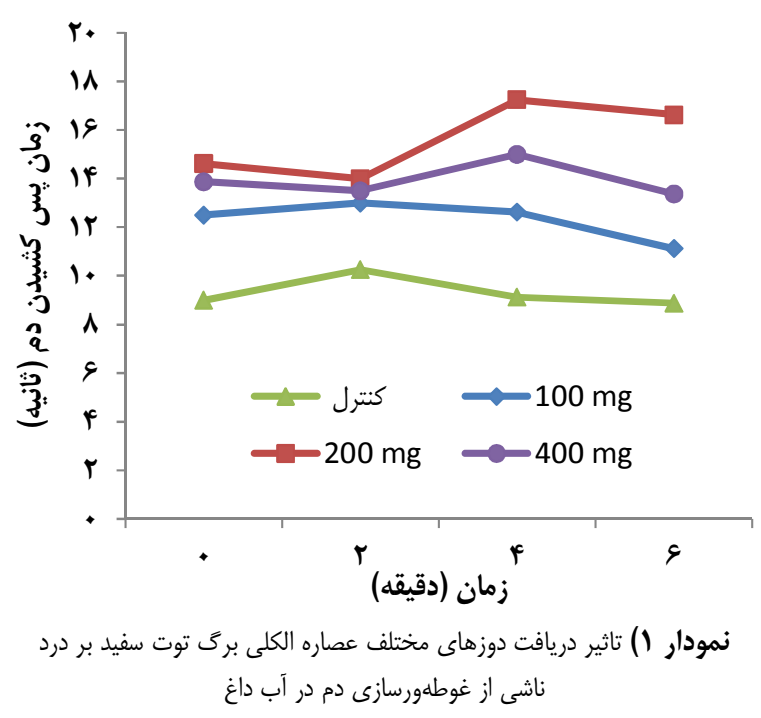

ميزان كشيدگى و انقباضات شكمى در موشهاى دريافتكننده

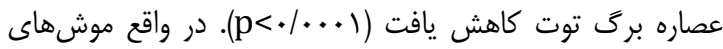
دريافتكننده عصاره درد كمترى را احساس كردند. كاهش درصد

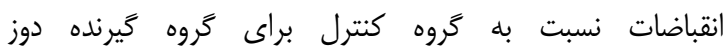

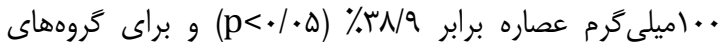

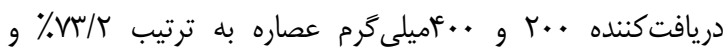

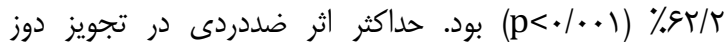

. . . . .

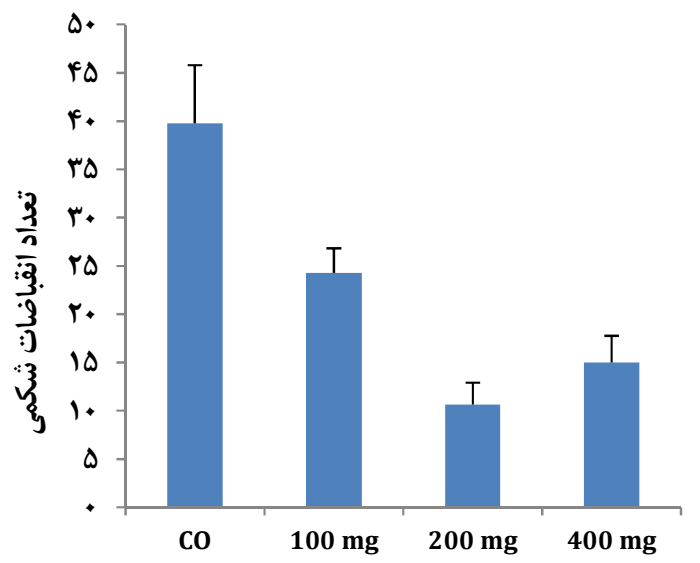

نمودار ץ) تاثير دريافت دوزهاى مختلف عصاره الكلى برك توت سفيد بر درد

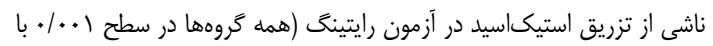
كروه كنترل اختلاف معنى دار داشتند)

دريافت عصاره الكلى برى توت باعث كاهش معنىدارى در احساس درد ناشى از تزريق فرمالين در هر دو فاز حاد (دقايق صفر

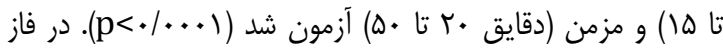

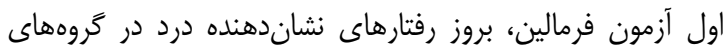

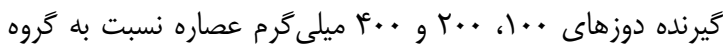


التهاب مى شود[43]. مشخص شده است كوئرستين موجود در خاى

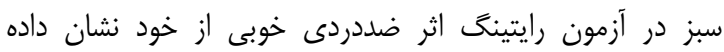

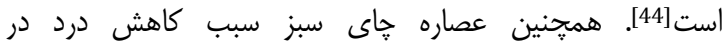
آزمونهاى فرمالين و وِ كشيدن دم در موشهاى صحاى صحرايى شده

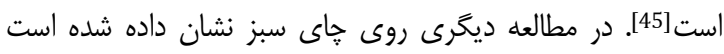

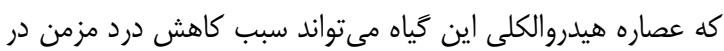

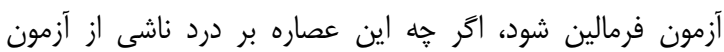

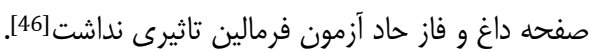

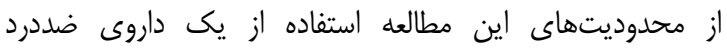

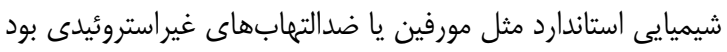

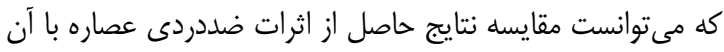

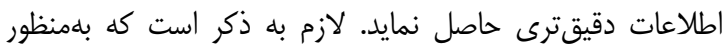

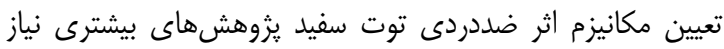

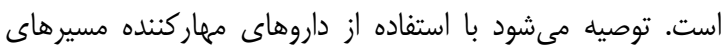

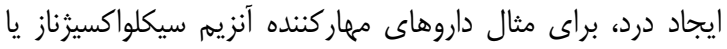

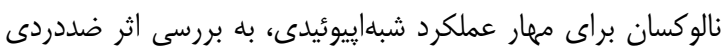

$$
\text { عصاره الكلى برك توت يرداخته شود. }
$$

\section{نتيجه كَيرى}

مصرف خوراكى عصاره الكلى برك توت سفيد باعث كاهش درث

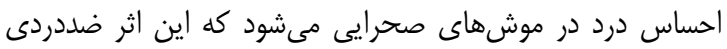

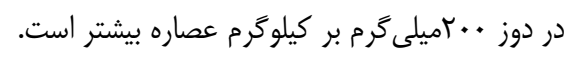

تشكر و قدردانى: مقاله حاضر حاصل بخشى از نتايج طرح

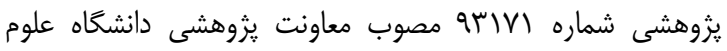

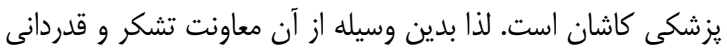

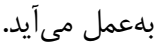
تاييديه اخلاقى: تمامى دستورات اخلاقى مصوب كميته اخلاق

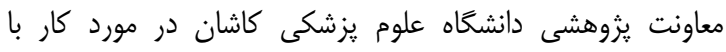

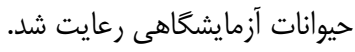
تعارض منافع: موردى توسط نويسندكان بيان نشده است.

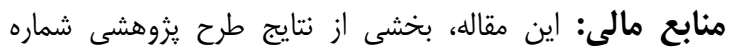
است

\section{منابع}

1- Blondell RD, Azadfard M, Wisniewski AM. Pharmacologic therapy for acute pain. Am Fam Physician. 2013;87(11):766-72.

2- Wong I, St John-Green C, Walker SM. Opioid-sparing effects of perioperative paracetamol and nonsteroidal anti-inflammatory drugs (NSAIDs) in children. Paediatr Anaesth. 2013;23(6):475-95.

3- Harirforoosh S, Asghar W, Jamali F. Adverse effects of nonsteroidal antiinflammatory drugs: an update of

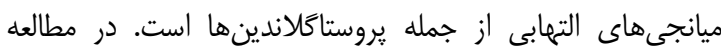

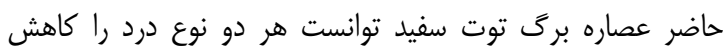

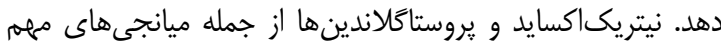

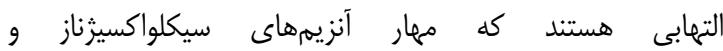
نيتريك|كسايدستتاز سبب كاهش مقادير نيتريكاكسايد و و

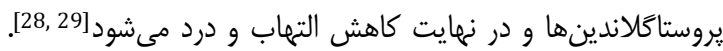

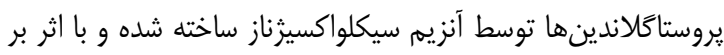

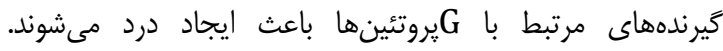

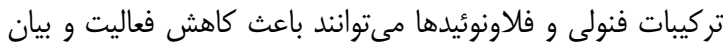

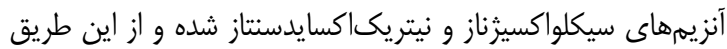

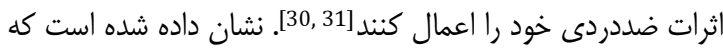

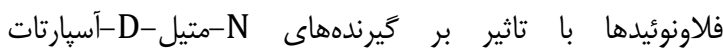
سبب كاهش كلسيم درونسلولى و بهدنبال آن مهار

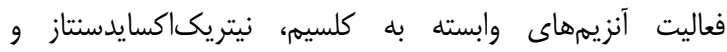

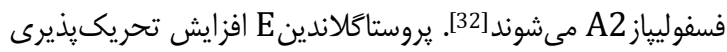

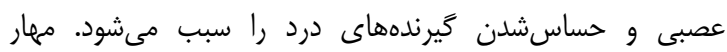

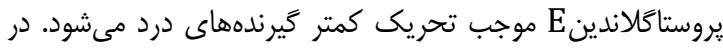

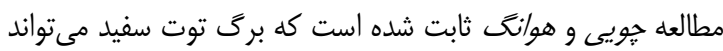

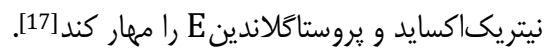

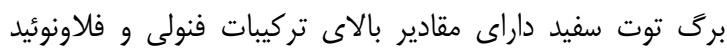

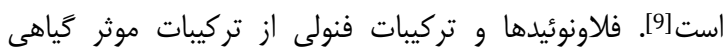

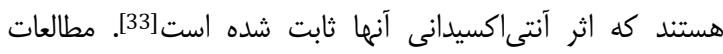

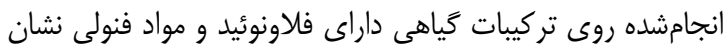

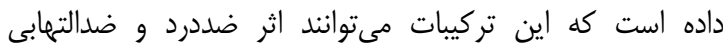

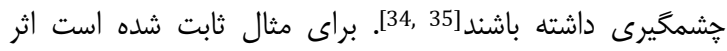

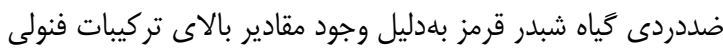

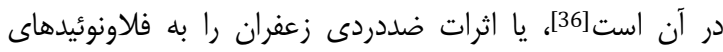

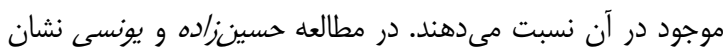
داده شده است كه عصاره زعفران داراى اثر ضددردى است. در ائ درد اين

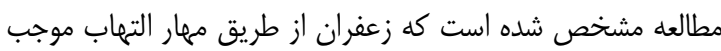

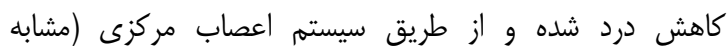

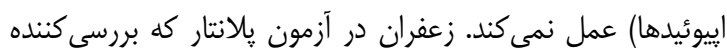

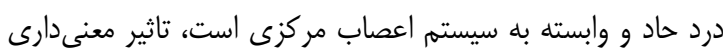

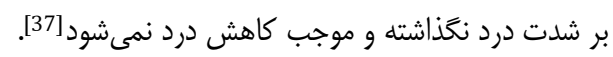

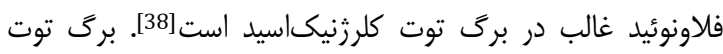
همجنين داراى روتين و بلميزان كمترى كوئرستين، ايزوكوئرستين

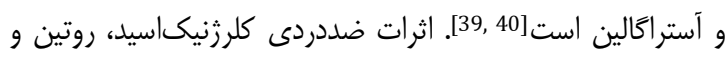

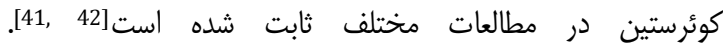

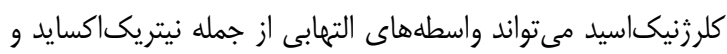
TNF- $\alpha$

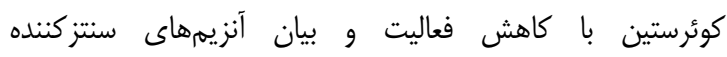
نيتريكاكسايد و سيكلواكسيزناز موجب كاهش بردردى ناشى از 
اثر ضددردى عصاره الكلى برى توت سفيد بر موشهاى صحرايى نر LVV spinosa Extracts. Jundishapur J Nat Pharm Prod. 2014;9(3):e13859.

22- Bannon AW, Malmberg AB. Models of nociception: hot-plate, tail-flick, and formalin tests in rodents. Curr Protoc Neurosci; 2007.

23- Abbott FV, Melzack R, Samuel C. Morphine analgesia in the tail-flick and formalin pain tests is mediated by different neural systems. Exp Neurol. 1982;75(3):644-51. 24- Coelho LP, Reis PA, de Castro FL, Gayer CRM, Lopes CdS, Silva MCdCe, et al. Antinociceptive properties of ethanolic extract and fractions of Pterodon pubescens Benth. seeds. J Ethnopharmacol. 2005;98(1-2):109-16.

25- Dubuisson D, Dennis SG. The formalin test: a quantitative study of the analgesic effects of morphine, meperidine, and brain stem stimulation in rats and cats. Pain. 1977;4(2):161-74.

26- Arzi A, Rezaei M, Aghel N, Nouri Mombeyni S. Effect of white mulberry leaves hydro-alcoholic extract on carrageenan-induced inflammation in male rat's hind paw. Jundishapur Sci Med J. 2009;8(2):149-56. [Persian] 27- de Mesquita Padilha M, Vilela FC, da Silva MJ, dos Santos MH, Alves-da-Silva G, Giusti-Paiva A. Antinociceptive effect of the extract of Morus nigra leaves in mice. J Med Food. 2009;12(6):1381-5.

28- Sakata K, Hirose Y, Qiao Z, Tanaka T, Mori H. Inhibition of inducible isoforms of cyclooxygenase and nitric oxide synthase by flavonoid hesperidin in mouse macrophage cell line. Cancer Lett. 2003;199(2):139-45.

29- Souto FO, Zarpelon AC, Staurengo-Ferrari L, Fattori $\mathrm{V}$, Casagrande R, Fonseca MJ, et al. Quercetin reduces neutrophil recruitment induced by CXCL8, LTB4, and fMLP: inhibition of actin polymerization. J Nat Prod. 2011;74(2):113-8.

30- Mann GE, Rowlands DJ, Li FY, de Winter P, Siow RC. Activation of endothelial nitric oxide synthase by dietary isoflavones: Role of NO in Nrf2-mediated antioxidant gene expression. Cardiovasc Res. 2007;75(2):261-74.

31- Santangelo C, Vari R, Scazzocchio B, Di Benedetto R, Filesi C, Masella R. Polyphenols, intracellular signalling and inflammation. Ann Ist Super Sanita. 2007;43(4):394405.

32- Hu J, Wang Z, Guo Y-Y, Zhang X-N, Xu Z-H, Liu S-B, et al. A role of periaqueductal grey NR2B-containing NMDA receptor in mediating persistent inflammatory pain. Mol Pain. 2009;5:71-6.

33- da Silva BP, Bernardo RR, Parente JP. Flavonol glycosides from Costus spicatus. Phytochem. 2000;53(1):87-92.

34- Denny C, Melo PS, Franchin M, Massarioli AP, Bergamaschi KB, de Alencar SM, et al. Guava pomace: a new source of anti-inflammatory and analgesic bioactives. BMC. 2013;13:235.

35- Krogh R, Kroth R, Berti C, Madeira AO, Souza MM, Cechinel-Filho $\mathrm{V}$, et al. Isolation and identification of compounds with antinociceptive action from Ipomoea pes-caprae (L.) R. Br. Pharm. 1999;54(6):464-6.

36- Lam AN, Demasi M, James MJ, Husband AJ, Walker C. Effect of red clover isoflavones on cox-2 activity in murine and human monocyte/macrophage cells. Nutr Cancer. 2004;49(1):89-93.

37- Hosseinzadeh H, Younesi HM. Antinociceptive and anti-inflammatory effects of Crocus sativus L. stigma and petal extracts in mice. BMC Pharmacol. 2002;2:7.

38- Bagdas D, Cinkilic N, Ozboluk HY, Ozyigit MO, Gurun MS. Antihyperalgesic activity of chlorogenic acid in experimental neuropathic pain. J Nat Med. 2013;67(4):698-704.

Q Horizon Med Sci

Vol. 22, Iss. 2, Spr 2016 gastrointestinal, cardiovascular and renal complications. J Pharm Pharm Sci. 2013;16(5):821-47.

4- Roome T, Dar A, Naqvi S, Choudhary MI. Evaluation of antinociceptive effect of Aegiceras corniculatum stems extracts and its possible mechanism of action in rodents. J Ethnopharmacol. 2011;135(2):351-8.

5- Toker G, Küpeli E, Memisoğlu M, Yesilada E. Flavonoids with antinociceptive and anti-inflammatory activities from the leaves of Tilia argentea (silver linden). J Ethnopharmacol. 2004;95(2-3):393-7.

6- Oki T, Kobayashi M, Nakamura T, Okuyama A, Masuda $\mathrm{M}$, Shiratsuchi $\mathrm{H}$, et al. Changes in radical-scavenging activity and components of mulberry fruit during maturation. J Food Sci. 2006;71(1):C18-22.

7- El-Beshbishy HA, Singab AN, Sinkkonen J, Pihlaja K. Hypolipidemic and antioxidant effects of Morus alba L. (Egyptian mulberry) root bark fractions supplementation in cholesterol-fed rats. Life Sci. 2006;78(23):2724-33.

8- Kim SY, Gao JJ, Lee WC, Ryu KS, Lee KR, Kim YC. Antioxidative flavonoids from the leaves of Morus alba. Arch Pharm Res. 1999;22(1):81-5.

9- Katsube T, Tsurunaga $Y$, Sugiyama M, Furuno T, Yamasaki Y. Effect of air-drying temperature on antioxidant capacity and stability of polyphenolic compounds in mulberry (Morus alba L.) leaves. Food Chem. 2009;113(4):964-9.

10- Havsteen BH. The biochemistry and medical significance of the flavonoids. Pharmacol Ther. 2002;96(2-3):67-202.

11- Pandey KB, Rizvi SI. Plant polyphenols as dietary antioxidants in human health and disease. Oxid Med Cell Longev. 2009;2(5):270-8.

12- Sies H, Schewe T, Heiss C, Kelm M. Cocoa polyphenols and inflammatory mediators. Am J Clin Nutr. 2005;81(Suppl 1):304S-12s.

13- Yoon JH, Baek SJ. Molecular targets of dietary polyphenols with anti-inflammatory properties. Yonsei Med J. 2005;46(5):585-96.

14- Ercisli S, Orhan E. Chemical composition of white (Morus alba), red (Morus rubra) and black (Morus nigra) mulberry fruits. Food Chem. 2007;103(4):1380-4.

15- Zhishen J, Mengcheng T, Jianming W. The determination of flavonoid contents in mulberry and their scavenging effects on superoxide radicals. Food Chem. 1999;64(4):555-9.

16- Andallu B, Kumar AV, Varadacharyulu NC. Oxidative stress in streptozocin-diabetic rats: Amelioration by mulberry (Morus Indica L.) leaves. Chin J Integr Med. 2012;1:1-6.

17- Choi EM, Hwang JK. Effects of Morus alba leaf extract on the production of nitric oxide, prostaglandin E2 and cytokines in RAW264.7 macrophages. Fitoterapia. 2005;76(7-8):608-13.

18- Arabshahi-Delouee S, Urooj A. Antioxidant properties of various solvent extracts of mulberry (Morus indica L.) leaves. Food Chem. 2007;102(4):1233-40.

19- Özgena M, Serçeb S, Kayac C. Phytochemical and antioxidant properties of anthocyanin-rich Morus nigra and Morus rubra fruits. Sci Hortic. 2009;119(3):275-9.

20- de Souza MM, Bittar M, Cechinel-Filho V, Yunes RA, Messana I, Delle Monache F, et al. Antinociceptive properties of morusin, a prenylflavonoid isolated from Morus nigra root bark. Z Naturforsch C. 2000;55(34):256-60.

21- Mahboubi M, Taghizadeh M, Kazempour N. Antimicrobial and Antioxidant Activities of Pycnocycla 
2008;31(6):713-21.

43- Izzi V, Masuelli L, Tresoldi I, Sacchetti P, Modesti A, Galvano F, et al. The effects of dietary flavonoids on the regulation of redox inflammatory networks. Front Biosci (Landmark Ed). 2012;17:2396-418.

44- Valerio DA, Georgetti SR, Magro DA, Casagrande R, Cunha TM, Vicentini FT, et al. Quercetin reduces inflammatory pain: inhibition of oxidative stress and cytokine production. J Nat Prod. 2009;72(11):1975-9.

45- Singal A, Anjaneyulu M, Chopra K. Modulatory role of green tea extract on antinociceptive effect of morphine in diabetic mice. J Med Food. 2005;8(3):386-91.

46- Ahmadian-Baghbadorani N, Azhdari-Zarmehri H, Puzesh S, Mousavi FS, Rajaei F. Antinociceptive effect of hydroalcoholic extract of green tea in male mice. Feyz. 2014;17(6):528-36. [Persian]
101

39- Katsube T, Imawaka N, Kawano Y, Yamazaki Y, Shiwaku K, Yamane Y. Antioxidant flavonol glycosides in mulberry (Morus alba L.) leaves isolated based on LDL antioxidant activity. Food Chem. 2006;97(1):25-31.

40- Khan MA, Rahman AA, Islam S, Khandokhar P, Parvin $\mathrm{S}$, Islam MB, et al. A comparative study on the antioxidant activity of methanolic extracts from different parts of Morus alba L. (Moraceae). BMC Res Notes. 2013;6(1):24.

41- Azevedo MI, Pereira AF, Nogueira RB, Rolim FE, Brito GA, Wong DV, et al. The antioxidant effects of the flavonoids rutin and quercetin inhibit oxaliplatininduced chronic painful peripheral neuropathy. Mol Pain. 2013;9:53.

42- Filho AW, Filho VC, Olinger L, de Souza MM. Quercetin: further investigation of its antinociceptive properties and mechanisms of action. Arch Pharm Res. 